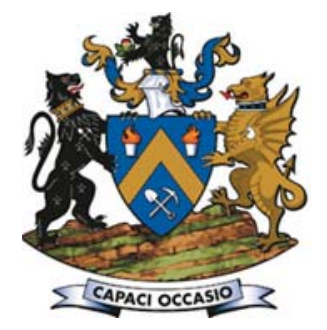

\title{
Potassium silicate concretes in sulphuric acid environments at ambient and low temperature in South Africa
}

\author{
by J.D. Hancock
}

\section{Synopsis}

The paper examines the ongoing development of quartz aggregate potassium silicate concretes at the $\mathrm{C} \& \mathrm{H}$ Laboratories. The original concrete using a sodium fluosilicate setting agent was found to have site problems in South Africa under certain conditions, but not in the UK. The bonding system was modified for local applications, and examples of successful site applications are provided. During 2016 an alternative setting agent only available in South Africa was identified, and this has led to the work on a new acid-resistant concrete that utilizes solid potassium silicate rather than a liquid silicate.

\section{Keywords}

acid-resistant concrete, crushing strength, setting agent, sodium fluosilicate, potassium silicate.

\section{Introduction}

Over 20 years ago, C\&H Laboratories, a refractory testing and development laboratory, was requested to develop an acid-resistant concrete for flooring and bund areas that was user-friendly and suitable for installation under typical South African site conditions.

The refractory industry in South Africa has a long history of involvement in acid-resistant materials. Acid-resistant bricks were made in South Africa for many years by Vereeniging Refractories until the closure of the plant in 2016. Figure 1 shows a cut section of a semivitrified red acid brick with a typical black core.

All alumina-silicate bricks have good resistance to acid attack and the choice of red, fawn, white acid, or even andalusite bricks was frequently based on price versus the available size tolerances of each grade.

Potassium silicate lining materials have been commercially available overseas for many years and are recognized for their excellent resistance to all acids except hydrofluoric acid (Corrosionengineering.com, 2006). Typically, such potassium silicate materials were based on a siliceous aggregate and sodium fluosilicate as a setting agent. The potassium silicate was supplied in large drums for addition on-site. The standard crushing strength of such concretes was $14 \mathrm{MPa}$ after 1 day and 24-28 MPa after the final cure was reached after 7 days.

One special note pertains to many of these products. Once it has set and will be exposed to water before it is exposed to acid, the surface needs to be pre-treated with an acid mixture of 1 part commercial strength (33\%) hydrochloric acid to 2 parts water. For applications in South Africa it would be an advantage to find a formulation that would be stable to water without the need for acid pretreatment.

Although the use of fluosilicate and a condensed aluminium phosphate is prohibited as the setting agent in some European specifications, it is used locally. Only one sample of such a concrete was found for testing and hence the results may not be typical of such products. Crushing strength after 1 day was 6-14 MPa, and 11-25 MPa after 28 days.

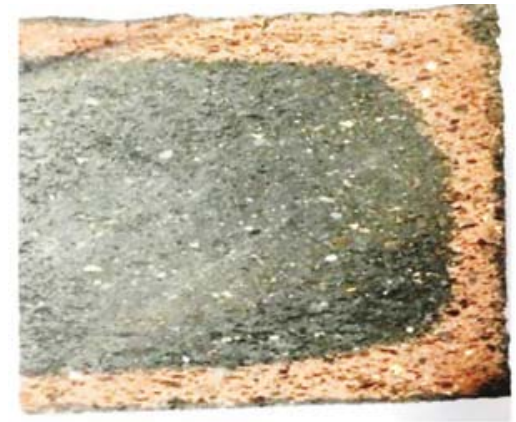

Figure 1-Cut section of a red acid brick

* C\&H Group of Companies, South Africa.

(c) The Southern African Institute of Mining and Metallurgy, 2017. ISSN 2225-6253. This paper was first presented at the $6^{\text {th }}$ Sulphuric Acid 2017 Conference', 9-12 May 2017, Southern Sun Cape Sun, Cape Town. 


\section{Potassium silicate concretes in sulphuric acid environments}

\begin{tabular}{|c|c|c|}
\hline Table & & \\
\hline Mass loss on & esistance te & \\
\hline Test method & Red acid brick & Andalusite VR 60 \\
\hline $\begin{array}{l}\text { Segar and Kramer } \\
\text { ASTM C279-511 }\end{array}$ & $\begin{array}{l}1.4 \text { to } 3.0 \\
5 \text { to } 7 \%\end{array}$ & $\begin{array}{l}1.2 \% \\
0.09 \%\end{array}$ \\
\hline
\end{tabular}

\section{Initial experimental work}

\section{Conventional concretes}

Crucibles and test cubes were cast using two concretes - both based on a quartz aggregate, with one using white Portland cement and the other a $50 \%$ alumina calcium aluminate cement. The latter had been developed a few years earlier for alkali-resistant flooring. Sulphuric acid concentrations of $20 \%$ and $50 \%$ were used for the tests. All tests had to be developed in-house as there are no definitive testing methods for acid-resistant castable.

The destruction of the white Portland concrete crucible by the $50 \%$ acid is shown in Figure 2. The damage to the crucible with the refractory cement was less severe and is shown in Figure 3.

The test cubes in the immersion tests showed a major reduction in strength, with the sample in 50\% acid suffering complete destruction.

\section{Potassium silicate concretes}

A quartz aggregate concrete was formulated in the laboratory using potassium silicate liquid and sodium fluosilicate setting agent. Crushing strength after 24 hours was typically 25 $\mathrm{MPa}$, increasing to $30 \mathrm{MPa}$ after 1 day of air-drying. The product was stable in a static water immersion test after the air-drying.

This product was licensed for manufacture in South Africa and good results were obtained with a wide range of acids, including sulphuric. However, one consideration quickly became apparent as regards the finishing off of such linings when cast as floors rather than cast behind

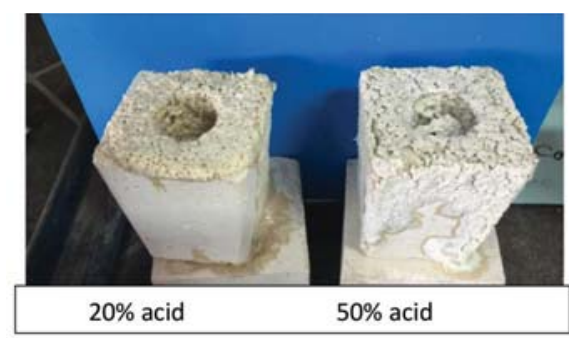

Figure 2-Acid testing of white Portland concrete

\begin{tabular}{|c|c|}
\hline \multicolumn{2}{|c|}{$\begin{array}{l}\text { Table } \\
\text { Immersion testing of refractory concrete ( } 30 \text { days' } \\
\text { exposure) }\end{array}$} \\
\hline Medium & Change in crushing strength relative to sample in ai \\
\hline $\begin{array}{l}\text { Water } \\
20 \% \text { acid } \\
50 \% \text { acid }\end{array}$ & $\begin{array}{c}-37 \% \\
-37 \% \\
\text { Expansile destruction }\end{array}$ \\
\hline
\end{tabular}

shuttering. Potassium silicate concretes tend to form a skin on exposure to wind or direct sunlight, and finishing of an installation must be completed before this occurs. The walls of the structure shown in Figure 4 were cast behind shuttering, but the surface tears in the floor had to be patched with a mortar version of the castable.

As a result of its success in South Africa the product technology was licensed to the UK. Some clients requested independent testing of the resistance to acid attack, and the results of one such test are shown in Table III. The test samples were immersed in 50\% sulphuric acid 18 hours after casting.

Over $150 \mathrm{t}$ of the concrete was supplied for use in sulphur pits at ADGAS in the UAE, Exxon plants in Baytown and Singapore, and the Shell plant at Stanlow UK. Applications in plants at which contact with sulphuric acid can occur are listed in Table IV.

\section{The problem in South Africa}

While no problem was ever reported in any of the sulphuric acid applications in the UK, a very specific problem was encountered on one site in South Africa. An example of the effect is shown in Figure 5.

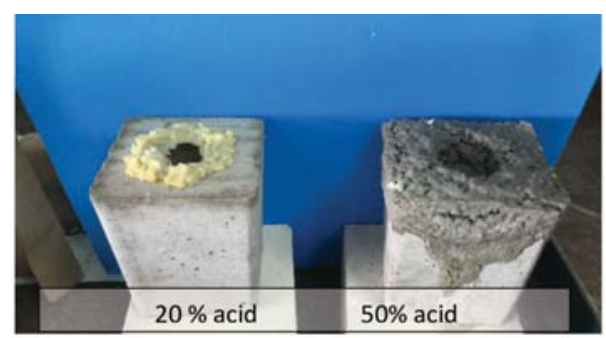

Figure 3-Acid testing of refractory concrete

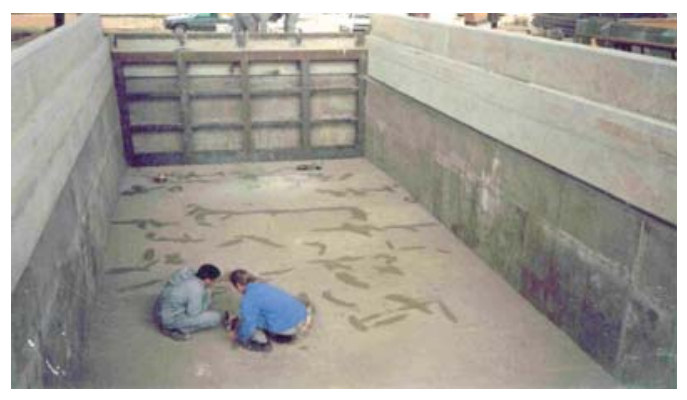

Figure 4-Surface tearing of a potassium silicate concrete floor

\section{UK acid immersion test results in $50 \%$ sulphuric acid}

\begin{tabular}{|l|c|c|}
\hline Sample size & Age (d) & Cold crushing stength (MPa) \\
\hline $100 \times 100 \times 100 \mathrm{~mm}$ & 28 & 36.0 \\
$100 \times 100 \times 100 \mathrm{~mm}$ & 56 & 38.0 \\
\hline
\end{tabular}

Soil Mechanics Civils (UK) tested to BS EN 12390-2000 Data supplied by R. Bowmer, Durosil Products UK 


\section{Potassium silicate concretes in sulphuric acid environments}

\begin{tabular}{|l|c|}
\hline \multicolumn{2}{|l|}{ Table } \\
\multicolumn{2}{|l|}{ Applications in the UK chemical industry } \\
\hline Lambson Chemicals & Bridgewater \\
Zenecca DTBA & Seal Sands \\
Rhodia & Chesterfield \\
Huntsman Tioxide & Grimsby \\
UCB Films & Wigan \\
United Utilitie & Rochdale \\
Albion Chemicals & Sandbach \\
Great Lakes Chemicals & Amiwch \\
Surface Specialities & Wigton \\
Incos Chlor & Runcorn \\
Yuasa Batteries & - \\
Tungstone Batteries & - \\
\hline
\end{tabular}

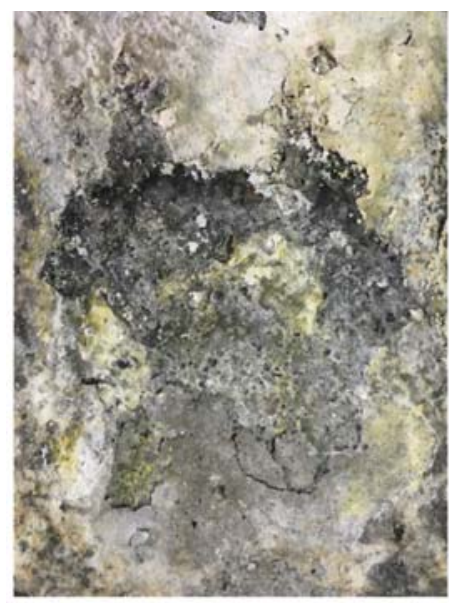

Figure 5-Surface scaling of acid-resistant concrete in wet/dry sulphuric acid conditions

According to some very old commercial literature (J. Crosfield \& Sons, 1965) this surface scaling is associated with the expansile crystallization of sodium sulphate on a dry surface. In the UK there is a standard whereby the acid surface is kept constantly wet. However, no mention of this effect could be found in any documents published in the last 15 years. Consequently, some additional experimental work was undertaken.

\section{Additional experimental work}

The standard acid concrete was cast as $76 \times 76 \times 76 \mathrm{~mm}$ cubes and crucibles for testing with $20 \%$ and $50 \%$ sulphuric acid. A reference cube was used for a comparison of the 30-day strength in air. The cubes were air-dried for 3 days and then totally immersed in the liquids for 30 days. The crucibles were filled with liquid and topped up as required. The results of these tests (Table V) show some reduction in strength compared to the water-immersed and air-dried reference sample. This contrasts with the results of the UK laboratory tests, in which the cubes were not allowed to air-dry but were stripped from the moulds and placed directly into the acid.

The crucible tests, designed to simulate a wet to dry environment, showed surface scaling of the sample with $20 \%$ acid, but no scaling with $50 \%$ acid (Figure 6).

\begin{tabular}{|l|l|}
\hline $\begin{array}{l}\text { Table } \\
\text { Immersion testing of standard acid concrete } \\
\text { (30 days' exposure) }\end{array}$ \\
\hline Medium & Change in crushing strength relative to air value \\
\hline Water & Nil \\
$20 \%$ sulphuric acid & $-15 \%$ \\
$50 \%$ sulphuric acid & $-5 \%$ \\
\hline
\end{tabular}

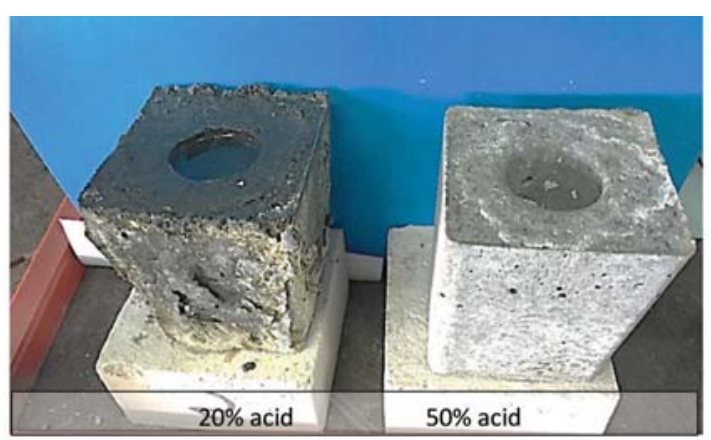

Figure 6-Surface scaling of acid concrete with $20 \%$ acid

$$
\begin{aligned}
& \text { Table VI } \\
& \text { Immersion testing of modified concrete }
\end{aligned}
$$

\begin{tabular}{|l|c|}
\hline $\begin{array}{l}\text { S-Grade concrete } \\
\text { exposed for } \mathbf{3 0} \text { days }\end{array}$ & $\begin{array}{c}\text { Change in crushing strength } \\
\text { relative to air sample }\end{array}$ \\
\hline Water & $\mathrm{Nil}$ \\
$20 \%$ acid & $-5 \%$ \\
$50 \%$ acid & $\mathrm{Nil}$ \\
\hline
\end{tabular}

\section{Formulation of S-Grade}

Mixes were prepared in the laboratory with a reduced level of fluosilicate plus additives which might modify the chemistry and prevent the surface scaling.

One additive was found to be very successful and the results of crucible and cube tests are shown in Figure 7 and Table VI.

There have been many applications of the S-Grade silicate concrete in sulphuric acid conditions in South Africa. Some of these are shown in Table VII

\section{Installation advantages}

The following information was gathered from on-site observations during installations. This is to give an indication of the benefits of using a castable rather than any other acid-proofing methods.

(a) High slump concrete that can be mixed and installed with civil concrete equipment and methods

(b) Low permeability with no apparent cracking or shrinkage, therefore there is no need to install a membrane

(c) Casting in panels entails fewer joints, which results in no penetration at joints due to crystallization of chemicals in joints 


\section{Potassium silicate concretes in sulphuric acid environments}

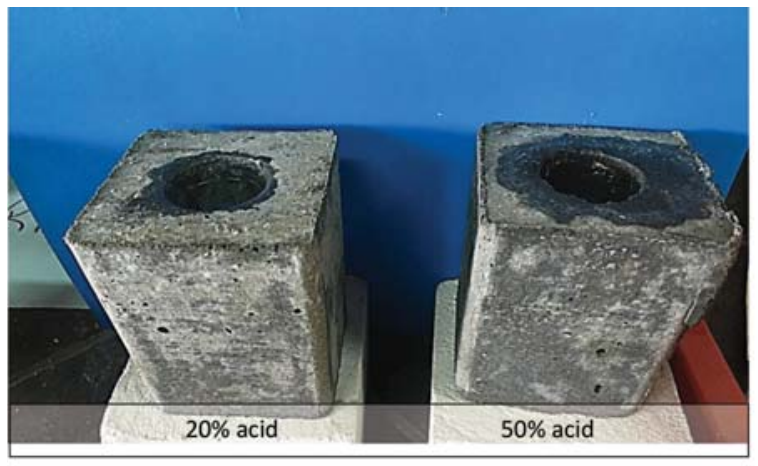

Figure 7-S-Grade concrete with no surface scaling

\section{Table}

Some larger applications of the modified concrete in sulphuric acid conditions

\begin{tabular}{|l|c|c|}
\hline Date & Location & Application \\
\hline 2012 & Secunda & Loading bay road \\
2012 & Natal & Sugar mills \\
2012 & Phalaborwa & Fertilzer plant \\
2013 & Phalaborwa & Fertilizer plant \\
2014 & Sasolburg & Sulphur pit \\
2014 & Nelspruit & Loading bay road \\
2014 & Nelspruit & Bund floor \\
2014 & Nelspruit & Bund wall \\
2015 & Gauteng & Bund area \\
2015 & Phalaborwa & Loading bay road \\
2015 & Nelspruit & Bund area \\
2015 & Nelspruit & Acid pit \\
2015 & Gauteng & Bund area \\
2015 & Mpumalanga & Bund area \& road \\
2015 & Secunda & Bund area \\
2016 & Gauteng & Bund area \\
2016 & Secunda & Bund area \\
2016 & Phalaborwa & Fertilizer plant \\
2016 & Nelspruit & Channel \\
2016 & North west & Bund area \\
& & \\
\hline
\end{tabular}

Burger, P. Burg Refractories South Africa

(d) Set equipment on castable structure and overlays in 24 hours (at $21^{\circ} \mathrm{C}$ )

(e) Stable in the presence of water

(f) No need to wait 28 days for concrete to dry out to $10 \%$ moisture, as it can be laid on green concrete

(g) Can be laid over dried acid-attacked concrete after removal of loose materials and acid residue

(h) No cutting around plinth ensures better sealing

(i) Precast shapes for weir wall, guide blocks, gulleys, troughs etc. can be cast in days

(j) Excellent adhesion to civil concrete, earthworks, and acid-resistant brick

(k) Quick installation time compared with cutting, shaping, or more traditional methods.

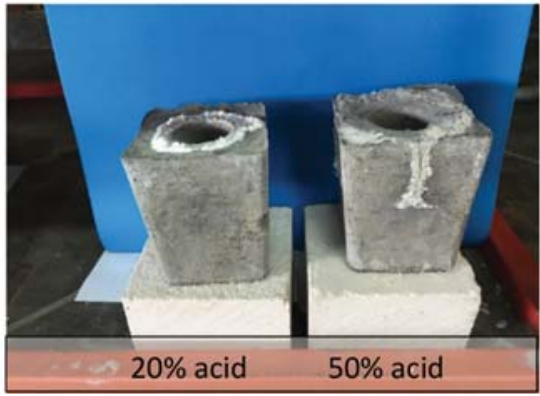

Figure 8-Crucible tests with powder potassium silicate

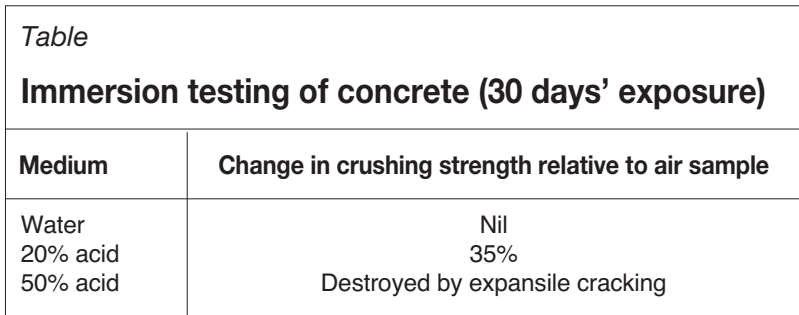

\section{New setting agent 2016}

An ideal potassium silicate concrete for site work would involve just the addition of water to a dry bagged material containing a soluble potassium silicate powder and setting agent.

In 2016 a locally manufactured material was identified as a possible setting agent for use with dry powder potassium silicate. The results of initial strength and acid resistance tests looked very promising. The reaction mechanism was based on soluble boric acid in the setting agent reacting with the soluble potassium silicate in water. Unfortunately, tests with sulphuric acid showed both cracking and a significant strength reduction (Figure 8 and Table VIII).

\section{Conclusions}

The original formulation of the acid-resistant concrete continues to be used in the UK and no problems of surface scaling have been reported by the technology licensor. The manufacture of this product was discontinued in South Africa following the scaling problem on one site, and it was replaced by the S-Grade version in 2009. No problems with scaling have been reported from any site.

The ideal concrete for site use would be a totally dry mix utilizing a powdered potassium silicate and no requirement for an acid pre-wash. Laboratory work is continuing to find a setting agent that will function in sulphuric acid conditions.

\section{References}

Corrosionengineering.com. 2006. The amazing acid resistance of potassium silicate concrete http://www.corrosion-

engineering.com/newsletterarticleshtml/TheAmazingAcidResistanceofPota ssiumSilicateConcrete.html

J. CROSFIELD \& Sons UK. 1965. Silicate brochure. Reviewed and reprinted May, 1965. 